\title{
Stereotactic Irradiation of GH-Secreting Pituitary Adenomas
}

\author{
G. Minniti, ${ }^{1,2}$ C. Scaringi, ${ }^{2}$ D. Amelio, ${ }^{3}$ and R. Maurizi Enrici ${ }^{2}$ \\ ${ }^{1}$ Department of Neuroscience, Neuromed Institute, 86077 Pozzilli, Italy \\ ${ }^{2}$ Department of Radiation Oncology, Sant'Andrea Hospital, University Sapienza, 00189 Rome, Italy \\ ${ }^{3}$ ATreP, Agenzia Provinciale per la Protonterapia, 38122 Trento, Italy \\ Correspondence should be addressed to G. Minniti, gminniti@ospedalesantandrea.it \\ Received 30 September 2011; Accepted 14 December 2011 \\ Academic Editor: A. L. Barkan
}

Copyright ( 2012 G. Minniti et al. This is an open access article distributed under the Creative Commons Attribution License, which permits unrestricted use, distribution, and reproduction in any medium, provided the original work is properly cited.

Radiotherapy (RT) is often employed in patients with acromegaly refractory to medical and/or surgical interventions in order to prevent tumour regrowth and normalize elevated GH and IGF-I levels. It achieves tumour control and hormone normalization up to $90 \%$ and $70 \%$ of patients at $10-15$ years. Despite the excellent tumour control, conventional RT is associated with a potential risk of developing late toxicity, especially hypopituitarism, and its role in the management of patients with GH-secreting pituitary adenomas remains a matter of debate. Stereotactic techniques have been developed with the aim to deliver more localized irradiation and minimize the long-term consequences of treatment, while improving its efficacy. Stereotactic irradiation can be given in a single dose as stereotactic radiosurgery (SRS) or in multiple doses as fractionated stereotactic radiotherapy (FSRT). We have reviewed the recent published literature on stereotactic techniques for GH-secreting pituitary tumors with the aim to define the efficacy and potential adverse effects of each of these techniques.

\section{Introduction}

GH-secreting pituitary adenoma is responsible for acromegaly, a disorder characterized by significant morbidity and mortality due to musculoskeletal, cardiovascular, metabolic, and pulmonary complications $[1,2]$.

Surgery, radiotherapy (RT), and medical therapies, including dopamine agonists, somatostatin-receptor ligands, and the GH-receptor antagonist pegvisomant are available treatments for patients with GH-secreting pituitary adenomas. Transsphenoidal surgery is often employed in the initial management of acromegaly. Remission of disease is achieved in up to $60 \%$ of patients [3] with a low incidence of surgical complications and significant improvement of metabolic and cardiovascular dysfunctions $[4,5]$. Somatostatin analogs are a safe and effective treatment for $\mathrm{GH}$-secreting adenomas, resulting in a normalization of GH/IGF-I hypersecretion in approximately $60-70 \%$ of patients [6]. RT is recommended only for patients with persistent active disease after surgery and/or during medical therapy, being able in normalizing GH/IGF-I in up to $70 \%$ of patients $10-15$ years after RT in several series [7-10]. However, efficacy and potential toxicity of RT remain matter of debate.
More recently, stereotactic radiation techniques have been employed in patients with GH-secreting pituitary adenomas to deliver more localized irradiation with a steeper dose gradient between the tumor and the surrounding normal tissue in order to minimize radiation-induced toxicity while improving its effectiveness [11]. The techniques either involve photon energy from multiple cobalt 60 radiation sources (gamma knife) or a modified linear accelerator (LINAC) and are given as a single fraction stereotactic radiosurgery (SRS) or as fractionated stereotactic radiotherapy (FSRT).

In this paper, we present a critical analysis of the more recent available literature on fractionated stereotactic radiotherapy and radiosurgery for $\mathrm{GH}$-secreting pituitary adenomas, in an attempt to define the efficacy, safety, and role of the individual stereotactic techniques.

\section{Stereotactic Techniques}

2.1. Stereotactic Radiosurgery (SRS). SRS using either a multiple cobalt-60 gamma radiation-emitting sources gamma knife (GK) or a LINAC has been extensively employed in the last two decades in patients with small brain tumors 
[12]. During SRS, patients are usually immobilized in a fixed frame with a positioning accuracy $<1 \mathrm{~mm}$, and a single, high dose of radiation is delivered to a well-defined tumor volume. The GK system is the most widely radiosurgical technique used for treating brain tumors and consists of an array of 201 cobalt- 60 sources that are arranged in a hemisphere and focused with a collimator helmet on a single or multiple points termed as isocenters. The best dose conformality is achieved by changing the number and the distribution of isocenters and the beam size by variation of collimator apertures. This results in a sharp-step-dose gradient between the tumor and the surrounding normal tissue, and small target may receive high doses while adjacent radiation-sensitive structures will receive negligible doses.

Instead of using an array of cobalt sources, Linac SRS utilizes X-rays which are derived from colliding accelerated electrons with a target metal. The treatment is delivered with the use of multiple arcs or beams resulting in high-dose differential between the target and normal brain tissue. Isodose gradients are improved by the use of multiple isocentre plans, intensity modulation of the beams, restriction of gantry angles and arc lengths, and microcollimation. Regardless the superiority in terms of dose delivery and distribution claimed for each of these techniques, the reported clinical efficacy and toxicity are similar.

CyberKnife (Accuray, Sunnyvale, CA) is a relatively new technological device which combines a mobile linear accelerator mounted on a robotic arm with an image-guided robotic system. The system allows for frameless SRS achieving the same level of targeting precision as frame-based SRS. Patients are fixed in a thermoplastic mask, and the treatment can be delivered in form of hypofractionated regimen in patients with tumors involving the optic apparatus and who are not suitable for SRS $[13,14]$.

Particle radiation has been also applied successfully in the treatment of pituitary adenomas. The physical properties of proton irradiation can offer superior conformality in dose distribution when compared to photons, and the advantage becomes more apparent for large volumes [15]. Proton therapy can be delivered as SRS or as FSRT with the same immobilization systems and target accuracy of photon techniques. Although potential benefit that may derives by the irradiation of larger tumors located close to critical anatomic structure, the superiority of protons in terms of clinical efficacy and reduced toxicity remains to be proven.

\subsection{Fractionated Stereotactic Radiotherapy (FSRT). FSRT is} a stereotactic technique in which a variable number of fractions are delivered to a target by a modified LINACbased accelerator. Although FSRT uses the same planning system as SRS, patients undergoing FSRT are usually immobilized in a high-precision frameless stereotactic fixation system, including infrared camera guidance [16], dental [17], implanted fiducial markers [18], and mask fixation system $[19,20]$ with a reported accuracy of $1-3 \mathrm{~mm}$. Thus, FSRT combines the precision of stereotactic technique with the biological advantages of fractionation. Large single doses of radiation are in fact more toxic to normal brain structures than similar doses given in a fractionated manner. FSRT is usually administered in 25-30 daily fractions of 1.8-2 Gy as for conventional RT; however, hypofractionated stereotactic radiotherapy (HSRT) in which a total dose of $20-40$ Gy is delivered in 3-7 fractions can be used in selected patients.

The decision on whether to use SRS or FSRT for pituitary tumors mainly depends on the volume of the target lesion and its proximity to sensitive structures. SRS is usually offered to patients with relatively small adenomas not in close proximity of the optic apparatus. A well-defined dosedependent risk of radiation optic neuropathy exists following single doses of irradiation, and current practice of SRS aims to avoid irradiating the optic apparatus to single doses beyond $10 \mathrm{~Gy}[21,22]$. Leber et al. [21] reported on 66 patients receiving RS for parasellar tumors. Optic neuropathy occurred in $0 \%, 26 \%$, and $78 \%$ of patients receiving doses less than $10 \mathrm{~Gy}, 10$ to $15 \mathrm{~Gy}$, and more than 15 Gy to the optic apparatus, respectively. Stafford et al. [22] reported an incidence of optic neuropathy of $2 \%$ in a series of 215 patients after treatment with SRS for skull base tumors. The rates of optic neuropathy were less than $2 \%$ for doses between 8 and $10 \mathrm{~Gy}$ and $6.9 \%$ for doses in excess of $12 \mathrm{~Gy}$. This means that SRS can be safely employed only for tumors at least $2-4 \mathrm{~mm}$ away from the optic chiasm, depending on size, position, and shape of the tumor, as well delivered dose and radiosurgical treatment techniques.

By contrast, there is no restriction to the size of pituitary adenoma suitable for SRT when a conventional fractionation is used, since the delivered total doses are within tolerance of normal brain structures, including the optic apparatus.

\section{Efficacy and Toxicity of Irradiation}

3.1. Stereotactic Radiosurgery. Results of 29 recent published studies including 1215 patients with $\mathrm{GH}$-secreting pituitary adenomas treated with SRS are showed in Table 1 [23-51]. At a corrected median followup of 50.6 months (range 6114 months), the reported tumor growth control following SRS is $98 \%$, ranging from 92 to $100 \%$. A variable biochemical remission of disease ranging from $17 \%$ to $82 \%$ has been reported, depending by the different lengths of followup and the criteria used to define the biochemical control of disease. When glucose-suppressed plasma GH levels during OGTT and normal age-corrected IGF-I values were used to define the biochemical remission of acromegaly according to recent criteria of endocrinologic cure [52], the 5-year hormonal normalization observed in 9 studies reporting 528 patients was $43 \%$ (range 15-60 months) [38, 42, 44-47]. Time to response ranged from 12 to 66 months. GK SRS is the most widely reported radiosurgical technique. Only few studies report on the use of linac SRS for GH-secreting tumors, although with a similar efficacy when compared with GK SRS.

In a retrospective analysis of 83 patients with acromegaly treated with GK SRS at University of Milan San Raffaele between 1994 and 2006, the reported actuarial biochemical remission rates were $30 \%, 52 \%$, and $85 \%$ at 3,5 , and 10 years, respectively [47]. Jezková et al. [41] in a series of 96 patients reported hormonal remission rates of $45 \%$ at 3 years, $58 \%$ at 
TABLE 1: Summary of results of recent series on SRS for GH-secreting pituitary adenomas.

\begin{tabular}{|c|c|c|c|c|c|c|c|c|}
\hline \multirow[t]{2}{*}{ Authors } & \multirow{2}{*}{$\begin{array}{l}\text { patients } \\
\text { No }\end{array}$} & \multirow{2}{*}{$\begin{array}{l}\text { Type of } \\
\text { SRS }\end{array}$} & \multirow{2}{*}{$\begin{array}{c}\text { Total } \\
\text { dose Gy }\end{array}$} & \multirow{2}{*}{$\begin{array}{l}\text { followup } \\
\text { median } \\
\text { (months) }\end{array}$} & \multirow{2}{*}{$\begin{array}{c}\text { Tumor } \\
\text { control (\%) }\end{array}$} & \multirow{2}{*}{$\begin{array}{c}\text { Hormone } \\
\text { normalization } \\
(\%)\end{array}$} & \multicolumn{2}{|c|}{ Late toxicity (\%) } \\
\hline & & & & & & & Visual & Hypopituitarism \\
\hline $\begin{array}{l}\text { Morange-Ramos et al. } \\
{[23]}\end{array}$ & 15 & GK SRS & 28 & 20 & NA & 20 & 5 & 16 \\
\hline Lim et al. [24] & 20 & GK SRS & 25 & 26 & 92.5 & 30 & 5 & 5 \\
\hline Landolt et al. [25] & 16 & GK SRS & 25 & 17 & NA & 50 & 0 & 0 \\
\hline Kim et al. [26] & 11 & GK SRS & 28.7 & 27 & NA & 35 & 0 & 0 \\
\hline Inoue et al. [27] & 12 & GK SRS & 21 & $>24$ & 94 & 58 & NA & NA \\
\hline Mokry et al. [28] & 10 & GK SRS & 16 & 46 & 100 & 31 & 0 & NA \\
\hline Izawa et al. [29] & 29 & GK SRS & 22.5 & $>6$ & 100 & 41 & 0 & 0 \\
\hline Zhang et al. [30] & 68 & GK SRS & 31 & 32 & NA & 40 & 1.3 & 4 \\
\hline Landolt et al. [31] & 31 & GK SRS & 25 & 19.2 & NA & 69 & NA & NA \\
\hline Ikeda et al. [32] & 17 & GK SRS & 25 & 58 & NA & 82 & 0 & 0 \\
\hline Pollock et al. [33] & 26 & GK SRS & 20 & 36 & 100 & 47 & 0 & 16 \\
\hline Swords et al. [34] & 13 & LINAC SRS & $8-15$ & 25 & 100 & 35 & 0 & 0 \\
\hline Choi et al. [35] & 12 & GK SRS & 28.5 & 43 & 100 & 30 & 0 & 0 \\
\hline Attanasio et al. [36] & 30 & GK SRS & 20 & 46 & 100 & 30 at 5 years & 0 & 6.7 \\
\hline Jane et al. [37] & 64 & GK SRS & 15 & $>18$ & NA & 36 & 0 & 28 \\
\hline Castinetti et al. [38] & 82 & GK SRS & 26 & $49.5^{*}$ & NA & 17 & 1.2 & 17 \\
\hline Gutt et al. [39] & 44 & GK SRS & 23 & 22 & 100 & 48 & NA & NA \\
\hline Kobayashi et al. [40] & 67 & GK SRS & 18,9 & 63 & 100 & 17 & 11 & 15 \\
\hline Jezková et al. [41] & 96 & GK SRS & 32 & 53.7 & 100 & 44 at 5 years & 0 & 27.1 \\
\hline Voges et al. [42] & 64 & LINAC SRS & 16,5 & 54.3 & 97 & $\begin{array}{l}14 \text { and } 33 \text { at } 3 \\
\text { and } 5 \text { years }\end{array}$ & 1.4 & $\begin{array}{c}13 \text { and } 18 \text { at } 3 \\
\text { and } 5 \text { years }\end{array}$ \\
\hline Petit et al. [43] & 22 & Proton SRS & $20 \mathrm{CGE}$ & 75.6 & 100 & 59 & 0 & 38 \\
\hline Pollock et al. [44] & 46 & GK SRS & 20 & 63 & 100 & $\begin{array}{l}11 \text { and } 60 \text { at } 2 \\
\text { and } 5 \text { years }\end{array}$ & 0 & 33 at 5 years \\
\hline Vik-Mo et al. [45] & 53 & GK SRS & 26.5 & 67 & 100 & $\begin{array}{l}58 \text { and } 86 \text { at } 5 \\
\text { and } 10 \text { years }\end{array}$ & 3.8 & 10 at 5 years \\
\hline $\begin{array}{l}\text { Jagannathan et al. } \\
\text { [46] }\end{array}$ & 95 & GK SRS & 22 & 57 & 98 & $\begin{array}{c}36 \text { and } 47 \text { at } 3 \\
\text { and } 5 \text { years }\end{array}$ & 4 & 34 \\
\hline Losa et al. [47] & 83 & GK SRS & 21,5 & 69 & 97 & $\begin{array}{l}52 \text { and } 85 \text { at } 5 \\
\text { and } 10 \text { years }\end{array}$ & 0 & 10 at 10 years \\
\hline Ronchi et al. [48] & 35 & GK SRS & 20 & 114 & 100 & $\begin{array}{l}15 \text { and } 46 \text { at } 5 \\
\text { and } 10 \text { years }\end{array}$ & 0 & 69 \\
\hline Wan et al. [49] & 103 & GK SRS & 21,4 & 67 & 95 & 37 & 0 & 6 \\
\hline Hayashi et al. [50] & 25 & GK SRS & 25.2 & 36 & 100 & 40 & 0 & 0 \\
\hline Iwai et al. [51] & 26 & GK SRS & 20 & 84 & 96 & $\begin{array}{l}17 \text { and } 47 \text { at } 5 \\
\text { and } 10 \text { years }\end{array}$ & 0 & 8 \\
\hline $\begin{array}{l}\text { Milker-Zabel et al. } \\
\text { [55] }\end{array}$ & 20 & FSRT & 52.2 & 61 & 100 & 80 at 5 years & 5 & 15 \\
\hline Colin et al. [56] & $31^{* *}$ & FSRT & 50.4 & 80 & 99 & $\begin{array}{l}20 \text { and } 50 \text { at } 5 \\
\text { and } 10 \text { years }\end{array}$ & 0 & 37 \\
\hline Minniti et al.[57] & $18^{* *}$ & FSRT & 45 & 39 & 98 & 50 at 5 years* & 0 & 22 \\
\hline Imran et al. [58] & 12 & FSRT & 50 & 28.5 & 92 & 33 & 0 & 8 \\
\hline Roug et al. [59] & 34 & FSRT & 54 & 45 & 91 & 36 at 5 years & NA & 29 \\
\hline
\end{tabular}

NA not assessed.

* mean followup; ** acromegalic patients included in series of FSRT for either secreting or non secreting pituitary tumors. 
5 years, and $57 \%$ at 8 years, respectively. Similar biochemical remission rates in the range of $45-60 \%$ at 5 years have been shown by others [44-46], although lower rates have been reported in some series [36, 38, 42, 51].

Remission of disease after SRS has been associated with pretreatment levels of GH and/or IGF-I levels in some series $[38,41,44,47]$ similar to that reported after conventional RT [7-10]. In a retrospective analysis of 46 consecutive patients 3 -year and 5-year biochemical remission rates were $40 \%$ and $90 \%$ for patients with IGF-I levels less than 2.25 times the upper limit of normal and $23 \%$ and $38 \%$ with IGFI levels greater than 2.25 times the upper limit of normal, respectively. Losa et al. [47] reported a median time for remission of 37 months for patients with pretreatment $\mathrm{GH}$ levels $\leq 7 \mu \mathrm{g} /$ liter as compared with 93 months for patients with $\mathrm{GH}$ levels $>7 \mu \mathrm{g} /$ liter. Although no relationship between baseline hormonal levels and remission of acromegaly has been reported in few series $[36,45]$, it seems reasonable that patients with near-normal GH and IGF-I levels are more likely to achieve hormonal remission than patients with markedly abnormal pretreatment levels.

Marginal doses of 15-34 Gy have been employed for the treatment of $\mathrm{GH}$-secreting pituitary adenomas. In the majority of studies, higher doses were not associated with higher rate of remission or faster normalization of GH/IGFI levels. Thus, a marginal dose of about 20-25 Gy seems appropriate to achieve either tumor control or hormonal normalization.

The concomitant use of somatostatin analogs at the time of SRS as negative predictor of biochemical remission remains matter of debate. Although in Landolt et al. [25] and Pollock et al. [33], series the use of somatostatin analogs at the time of SRS was correlated with a worse outcome, other authors found no differences in the outcome between patients who received somatostatin agonists at the time of GK and those who did not. Although somatostatin analogs withdrawal before SRS has gained an increase acceptance in clinical practice, future prospective studies are needed to elucidate the issue.

The reported overall rate of serious complications after SRS is low (Table 1). The most commonly observed complication following SRS for secreting adenomas was hypopituitarism, with an incidence ranging between 0 and $69 \%$, although hormonal function has not been systematically evaluated in most studies. In a series of 39 patients with acromegaly treated with GK SRS, a new pituitary deficit occurred in one-third of patients, with an actuarial incidence of hypopituitarism of $10 \%$ at 2 years and $33 \%$ at 5 years, respectively [27]. Jagannathan et al. [46] reported new endocrine deficiencies in $34 \%$ of 95 patients treated with GK SRS, and a similar incidence of hypopituitarism at 5 years has been observed in few other series [41, 45, 48]. Other treatment-related complications occur rarely after SRS. Cranial neuropathies, brain radionecrosis, and carotid artery stenosis have been reported infrequently following SRS. Loeffler et al. [53] reported two cases of secondary brain tumors after SRS for a pituitary adenoma. The risk to develop a new tumor after SRS appears to be significantly less than that seen following fractionated RT [54]; however, the relatively short length of followup of most published series does not allow for any definitive conclusion.

A recent experience of proton SRS showed a biochemical remission in $50 \%$ of 22 patients with $\mathrm{GH}$-secreting pituitary adenomas, with a median time to complete response of 30.5 months [43]. One-third of patients developed at least one new pituitary deficiency, requiring medical therapy. Based on this preliminary experience, the use of proton SRS does not seem to offer clinical advantages when compared to photons SRS.

3.2. Fractionated Stereotactic Radiotherapy. Five studies report on the use of FSRT in 115 patients with GH-secreting pituitary adenomas [54-59] (Table 1). At a median corrected followup of 54 months ranging from 28 to 80 months, the reported tumor control was $97 \%$. The median and 5year biochemical remission of disease were $40 \%$ and $42 \%$, being similar to the best reported rates of large studies of conventional RT and SRS. Milker-Zabel et al. [55] reported the normalization of elevated GH level in $70 \%$ of 20 acromegalic patients at a median of 26 months, with 5year local and hormonal control rates of $100 \%$ and $80 \%$, respectively. In a series of 18 patients with acromegaly treated with FSRT at Royal Marsden Hospital, biochemical remission was achieved in 35\% after a median followup of 39 months [54]. Actuarial normalization of GH/IGF-I levels was $20 \%$ at 3 years and $50 \%$ at 5 years. At a median followup of 30 months, Roug et al. [59] observed biochemical remission of disease, as defined by suppressed GH at OGTT and normal IGF-I levels adjusted for age, in 30\% of 34 patients with active acromegaly, being 24\%, 38\%, and 64\% after 1, 3, and 5 years, respectively.

A low-radiation-induced toxicity has been reported after FSRT, even in the case of large tumors involving the optic apparatus. Hypopituitarism has been reported in $8-37 \%$ of patients at median followup ranging from 28 to 82 months, whereas the reported incidence of optic neuropathy is $1-5 \%$. No cases of CVA and second tumors have been reported after FSRT. Since the incidence of such complications increases with time, large series and longer followups need to demonstrate the potential clinical advantages of treating less normal brain at high doses achieved with the use of the stereotactic techniques. Similarly, because of the lack of formal cognitive function testing and quality of life assessment after FSRT, the potential superiority of stereotactic techniques as compared with 3D conformal remains to be clarified.

Initial experiences with the application of CyberKnife in treating patients with acromegaly are promising $[60,61]$. In a report of nine patients with acromegaly treated with CyberKnife to doses of 18-24 Gy in one to three fractions, biochemical remission was observed in 4 patients at a mean followup of 25.4 months [61]. Whilst these results are promising, the short followup and the small number of patients do not permit any conclusion about the low risk of optic neuropathy in patients treated with hypofractionated regimens. When fractionation is thought to be safer than SRS, conventional fractionation should be considered on the basis of its proven efficacy and safety. 


\section{FSRS versus SRT}

There is much debate about the relative efficacy of SRS and SRT. Currently reported results suggest similar results in terms of tumor control and biochemical remission of acromegaly.

A faster decline of serum GH concentration after GK SRS as compared with FSRT has been reported by some authors $[25,62]$. In a small series of 16 patients with acromegaly, Landolt et al. [25] reported mean time to normalization of GH/IGF-I levels of 1.4 years in the group treated with the GK and 7.1 years in the group treated with FSRT. Mitsumori et al. [62] reported mean time to hormone normalization of 8.5 and 18 months in patients treated with SRS and FSRT, respectively. In contrast, recent series have showed a time to hormonal normalization following SRS of 30-66 months [36, 38, 41, 44-47] similar to that reported after fractionated RT $[55,57,59]$ and suggesting that time to hormonal normalization is more dependent on preirradiation GH/IGF-I levels than differences in radiation techniques. So far, the superiority of SRS in terms of time to hormonal normalization remains to be demonstrated. Data from stereotactic series suggest that the incidence of hypopituitarism after SRS is lower than that reported after fractionated RT; however, this may reflect different patient selection and length of followups, and large prospective studies are needed to clarify this issue.

In absence of comparative studies, the choice of the radiation technique is based on tumor characteristics. SRS is usually offered to patients with relatively small adenomas less than $3 \mathrm{~cm}$ in size and away more than $2-3 \mathrm{~mm}$ from the optic chiasm. FSRT should be preferred in patients with large tumors in close proximity of optic apparatus, since the treatment is delivered within the radiation tolerance limits of cranial nerves, including the optic apparatus.

\section{Conclusion}

SRS and FSRT represent effective treatment modalities of irradiation for patients with persistent active GH/IGF-I hypersecretion after surgery and/or during medical therapy, providing a comparable high rates of tumor control and endocrinological remission with low morbidity. Treating less normal brain by higher radiation doses is a clear technical improvement of modern RT which translates into clinical benefit in terms of reduction of late effects of radiation. In most centres, SRS is a convenient approach for patients with relatively small residual $\mathrm{GH}$-secreting tumors, while FSRT is usually reserved to patients with larger tumors not amenable to SRS. Prospective studies comparing SRS with FSRT would be of value to evaluate the long-term efficacy and toxicity of the techniques. Efficacy and toxicity of hypofractionated treatment schedules need to be explored in future studies.

\section{References}

[1] A. Colao, D. Ferone, P. Marzullo, and G. Lombardi, "Systemic complications of acromegaly: epidemiology, pathogenesis, and management," Endocrine Reviews, vol. 25, no. 1, pp. 102$152,2004$.

[2] S. Melmed, "Medical progress: acromegaly," The New England Journal of Medicine, vol. 355, pp. 2558-2573, 2006.

[3] G. Minniti, M. L. Jaffrain-Rea, V. Esposito, A. Santoro, G. Tamburrano, and G. Cantore, "Evolving criteria for postoperative biochemical remission of acromegaly: can we achieve a definitive cure? An audit of surgical results on a large series and a review of the literature," Endocrine-Related Cancer, vol. 10, no. 4, pp. 611-619, 2003.

[4] G. Minniti, C. Moroni, M. L. Jaffrain-Rea et al., "Marked improvement in cardiovascular function after successful transsphenoidal surgery in acromegalic patients," Clinical Endocrinology, vol. 55, no. 3, pp. 307-313, 2001.

[5] M. L. Jaffrain-Rea, G. Minniti, C. Moroni et al., "Impact of successful transsphenoidal surgery on cardiovascular risk factors in acromegaly," European Journal of Endocrinology, vol. 148, no. 2, pp. 193-201, 2003.

[6] M. Sherlock, C. Woods, and M. C. Sheppard, "Medical therapy in acromegaly," Nature Reviews Endocrinology, vol. 7, pp. 291300, 2011.

[7] G. Barrande, M. Pittino-Lungo, J. Coste et al., "Hormonal and metabolic effects of radiotherapy in acromegaly: long-term results in 128 patients followed in a single center," Journal of Clinical Endocrinology and Metabolism, vol. 85, no. 10, pp. 3779-3785, 2000.

[8] N. R. Biermasz, H. Van Dulken, and F. Roelfsema, "Longterm follow-up results of postoperative radiotherapy in 36 patients with acromegaly," Journal of Clinical Endocrinology and Metabolism, vol. 85, no. 7, pp. 2476-2482, 2000.

[9] G. Minniti, M. L. Jaffrain-Rea, M. Osti et al., "The long-term efficacy of conventional radiotherapy in patients with GHsecreting pituitary adenomas," Clinical Endocrinology, vol. 62, no. 2, pp. 210-216, 2005.

[10] P. J. Jenkins, P. Bates, M. N. Carson, P. M. Stewart, and J. A. H. Wass, "Conventional pituitary irradiation is effective in lowering serum growth hormone and insulin-like growth factor-I in patients with acromegaly," Journal of Clinical Endocrinology and Metabolism, vol. 91, no. 4, pp. 1239-1245, 2006.

[11] G. Minniti, D. C. Gilbert, and M. Brada, "Modern techniques for pituitary radiotherapy," Reviews in Endocrine and Metabolic Disorders, vol. 10, no. 2, pp. 135-144, 2009.

[12] M. Brada, T. V. Ajithkumar, and G. Minniti, "Radiosurgery for pituitary adenomas," Clinical Endocrinology, vol. 61, no. 5, pp. 531-543, 2004.

[13] J. R. Adler, I. C. Gibbs, P. Puataweepong, and S. D. Chang, "Visual field preservation after multisession CyberKnife radiosurgery for perioptic lesions," Neurosurgery, vol. 59, no. 2, pp. 244-254, 2006.

[14] B. D. Killory, J. J. Kresl, S. D. Wait, F. A. Ponce, R. Porter, and W. L. White, "Hypofractionated CyberKnife radiosurgery for Perichiasmatic Pituitary Adenomas: early results," Neurosurgery, vol. 64, supplement 2, pp. A19-A25, 2009.

[15] D. S. Gridley, R. S. Grover, L. N. Loredo, A. J. Wroe, and J. D. Slater, "Proton-beam therapy for tumors of the CNS," Expert Review of Neurotherapeutics, vol. 10, no. 2, pp. 319-330, 2010.

[16] J. M. Buatti, F. J. Bova, W. A. Friedman et al., "Preliminary experience with frameless stereotactic radiotherapy," International Journal of Radiation Oncology Biology Physics, vol. 42, no. 3, pp. 591-599, 1998.

[17] S. Kumar, K. Burke, C. Nalder et al., "Treatment accuracy of fractionated stereotactic radiotherapy," Radiotherapy and Oncology, vol. 74, no. 1, pp. 53-59, 2005. 
[18] K. H. Kim, M. J. Cho, J. S. Kim et al., "Isocenter accuracy in frameless stereotactic radiotherapy using implanted fiducials," International Journal of Radiation Oncology Biology Physics, vol. 56, no. 1, pp. 266-273, 2003.

[19] C. P. Karger, O. Jäkel, J. Debus, S. Kuhn, and G. H. Hartmann, "Three-dimensional accuracy and interfractional reproducibility of patient fixation and positioning using a stereotactic head mask system," International Journal of Radiation Oncology Biology Physics, vol. 49, no. 5, pp. 14931504, 2001.

[20] G. Minniti, M. Valeriani, E. Clarke et al., "Fractionated stereotactic radiotherapy for skull base tumors: analysis of treatment accuracy using a stereotactic mask fixation system," Radiation Oncology, vol. 5, no. 1, article 1, 2010.

[21] K. A. Leber, J. Bergloff, and G. Pendl, "Dose-response tolerance of the visual pathways and cranial nerves of the cavernous sinus to stereotactic radiosurgery," Journal of Neurosurgery, vol. 88, pp. 43-50, 1988.

[22] S. L. Stafford, B. E. Pollock, J. A. Leavitt et al., "A study on the radiation tolerance of the optic nerves and chiasm after stereotactic radiosurgery," International Journal of Radiation Oncology Biology Physics, vol. 55, no. 5, pp. 1177-1181, 2003.

[23] I. Morange-Ramos, J. Regis, H. Dufour et al., "Gamma-knife surgery for secreting pituitary adenomas," Acta Neurochirurgica, vol. 140, no. 5, pp. 437-443, 1998.

[24] Y. L. Lim, W. Leem, T. S. Kim, B. A. Rhee, and G. K. Kim, "Four years' experiences in the treatment of pituitary adenomas with gamma knife radiosurgery," Stereotactic and Functional Neurosurgery, vol. 70, supplement 1, pp. 95-109, 1998.

[25] A. M. Landolt, D. Haller, N. Lomax et al., "Stereotactic radiosurgery for recurrent surgically treated acromegaly: comparison with fractionated radiotherapy," Journal of Neurosurgery, vol. 88, no. 6, pp. 1002-1008, 1998.

[26] S. H. Kim, R. Huh, J. W. Chang, Y. G. Park, and S. S. Chung, "Gamma Knife radiosurgery for functioning pituitary adenomas," Stereotactic and Functional Neurosurgery, vol. 72, supplement 1, pp. 101-110, 1999.

[27] H. K. Inoue, H. Kohga, M. Hirato et al., "Pituitary adenomas treated by microsurgery with or without gamma knife surgery: experience in 122 cases," Stereotactic and Functional Neurosurgery, vol. 72, supplement 1, pp. 125-131, 1999.

[28] M. Mokry, S. Ramschak-Schwarzer, J. Simbrunner, J. C. Ganz, and G. Pendl, "A six year experience with the postoperative radiosurgical management of pituitary adenomas," Stereotactic and Functional Neurosurgery, vol. 72, supplement 1, pp. 88100, 1999.

[29] M. Izawa, M. Hayashi, K. Nakaya et al., "Gamma knife radiosurgery for pituitary adenomas," Journal of Neurosurgery, vol. 93, supplement 3, pp. 19-22, 2000.

[30] N. Zhang, L. Pan, J. Dai et al., "Gamma knife radiosurgery as a primary surgical treatment for hypersecreting pituitary adenomas," Stereotactic and Functional Neurosurgery, vol. 75, no. 2-3, pp. 123-128, 2000.

[31] A. M. Landolt, D. Haller, N. Lomax et al., "Octreotide may act as a radioprotective agent in acromegaly," Journal of Clinical Endocrinology and Metabolism, vol. 85, no. 3, pp. 1287-1289, 2000.

[32] H. Ikeda, H. Jokura, and T. Yoshimoto, "Transsphenoidal surgery and adjuvant gamma knife treatment for growth hormone-secreting pituitary adenoma," Journal of Neurosurgery, vol. 95, no. 2, pp. 285-291, 2001.

[33] B. E. Pollock, T. B. Nippoldt, S. L. Stafford, R. L. Foote, and C. F. Abboud, "Results of stereotactic radiosurgery in patients with hormone-producing pituitary adenomas: factors associated with endocrine normalization," Journal of Neurosurgery, vol. 97, no. 3, pp. 525-530, 2002.

[34] F. M. Swords, C. A. Allan, P. N. Plowman et al., "Stereotactic radiosurgery XVI: a treatment for previously irradiated pituitary adenomas," Journal of Clinical Endocrinology and Metabolism, vol. 88, no. 11, pp. 5334-5340, 2003.

[35] J. Y. Choi, J. H. Chang, J. W. Chang, Y. Ha, Y. G. Park, and S. S. Chung, "Radiological and hormonal responses of functioning pituitary adenomas after gamma knife radiosurgery," Yonsei Medical Journal, vol. 44, no. 4, pp. 602-607, 2003.

[36] R. Attanasio, P. Epaminonda, E. Motti et al., "Gamma-knife radiosurgery in acromegaly: a 4-year follow-up study," Journal of Clinical Endocrinology and Metabolism, vol. 88, no. 7, pp. 3105-3112, 2003.

[37] J. A. Jane Jr., M. L. Vance, C. J. Woodburn, and E. R. Laws Jr., "Stereotactic radiosurgery for hypersecreting pituitary tumors: part of a multimodality approach," Neurosurgical Focus, vol. 14, no. 5, article e12, 2003.

[38] F. Castinetti, D. Taieb, J. M. Kuhn et al., "Outcome of gamma knife radiosurgery in 82 patients with acromegaly: correlation with initial hypersecretion," Journal of Clinical Endocrinology and Metabolism, vol. 90, no. 8, pp. 4483-4488, 2005.

[39] B. Gutt, B. Wowra, R. Alexandrov et al., "Gamma-knife surgery is effective in normalising plasma insulin-like growth factor I in patients with acromegaly," Experimental and Clinical Endocrinology and Diabetes, vol. 113, no. 4, pp. 219224, 2005.

[40] T. Kobayashi, Y. Mori, Y. Uchiyama, Y. Kida, and S. Fujitani, "Long-term results of gamma knife surgery for growth hormone-producing pituitary adenoma: is the disease difficult to cure?" Journal of Neurosurgery, vol. 102, supplement, pp. 119-123, 2005.

[41] J. Jezková, J. Marek, V. Hána et al., "Gamma knife radiosurgery for acromegaly-long-term experience," Clinical Endocrinology, vol. 64, pp. 588-595, 2006.

[42] J. Voges, M. Kocher, M. Runge et al., "Linear accelerator radiosurgery for pituitary macroadenomas: a 7-year follow-up study," Cancer, vol. 107, no. 6, pp. 1355-1364, 2006.

[43] J. H. Petit, B. M. K. Biller, J. J. Coen et al., "Proton stereotactic radiosurgery in management of persistent acromegaly," Endocrine Practice, vol. 13, no. 7, pp. 726-734, 2007.

[44] B. E. Pollock, J. T. Jacob, P. D. Brown, and T. B. Nippoldt, "Radiosurgery of growth hormone-producing pituitary adenomas: factors associated with biochemical remission," Journal of Neurosurgery, vol. 106, no. 5, pp. 833-838, 2007.

[45] E. O. Vik-Mo, M. Oksnes, P. H. Pedersen et al., "Gamma knife stereotactic radiosurgery for acromegaly," European Journal of Endocrinology, vol. 157, no. 3, pp. 255-263, 2007.

[46] J. Jagannathan, J. P. Sheehan, N. Pouratian, E. R. Laws Jr., L. Steiner, and M. L. Vance, "Gamma knife radiosurgery for acromegaly: outcomes after failed transsphenoidal surgery," Neurosurgery, vol. 62, no. 6, pp. 1262-1269, 2008.

[47] M. Losa, L. Gioia, P. Picozzi et al., "The role of stereotactic radiotherapy in patients with growth hormone-secreting pituitary adenoma," Journal of Clinical Endocrinology and Metabolism, vol. 93, no. 7, pp. 2546-2552, 2008.

[48] C. L. Ronchi, R. Attanasio, E. Verrua et al., "Efficacy and tolerability of gamma knife radiosurgery in acromegaly: a 10year follow-up study," Clinical Endocrinology, vol. 71, no. 6, pp. 846-852, 2009.

[49] H. Wan, O. Chihiro, and S. Yuan, "MASEP gamma knife radiosurgery for secretory pituitary adenomas: experience in 347 consecutive cases," Journal of Experimental and Clinical Cancer Research, vol. 28, no. 1, article 36, 2009. 
[50] M. Hayashi, M. Chernov, N. Tamura et al., "Gamma Knife robotic microradiosurgery of pituitary adenomas invading the cavernous sinus: treatment concept and results in 89 cases," Journal of Neuro-Oncology, vol. 98, no. 2, pp. 185-194, 2010.

[51] Y. Iwai, K. Yamanaka, M. Yoshimura, I. Kawasaki, K. Yamagami, and K. Yoshioka, "Gamma knife radiosurgery for growth hormone-producing adenomas," Journal of Clinical Neuroscience, vol. 17, no. 3, pp. 299-304, 2010.

[52] A. Giustina, P. Chanson, M. D. Bronstein et al., "Acromegaly Consensus Group. A consensus on criteria for cure of acromegaly," The Journal of Clinical Endocrinology \& Metabolism, vol. 95, pp. 3141-3148, 2010.

[53] J. S. Loeffler, A. Niemierko, P. H. Chapman et al., "Second tumors after radiosurgery: tip of the iceberg or a bump in the road?" Neurosurgery, vol. 52, no. 6, pp. 1436-1442, 2003.

[54] G. Minniti, D. Traish, S. Ashley, A. Gonsalves, and M. Brada, "Risk of second brain tumor after conservative surgery and radiotherapy for pituitary adenoma: update after an additional 10 years," Journal of Clinical Endocrinology and Metabolism, vol. 90, no. 2, pp. 800-804, 2005.

[55] S. Milker-Zabel, A. Zabel, P. Huber, W. Schlegel, M. Wannenmacher, and J. Debus, "Stereotactic conformal radiotherapy in patients with growth hormone-secreting pituitary adenoma," International Journal of Radiation Oncology Biology Physics, vol. 59, no. 4, pp. 1088-1096, 2004.

[56] P. Colin, N. Jovenin, B. Delemer et al., "Treatment of pituitary adenomas by fractionated stereotactic radiotherapy: a prospective study of 110 patients," International Journal of Radiation Oncology Biology Physics, vol. 62, no. 2, pp. 333-341, 2005.

[57] G. Minniti, D. Traish, S. Ashley, A. Gonsalves, and M. Brada, "Fractionated stereotactic conformal radiotherapy for secreting and nonsecreting pituitary adenomas," Clinical Endocrinology, vol. 64, no. 5, pp. 542-548, 2006.

[58] S. Imran, I. Fleetwood, C. O'Connell et al., "Outcome of stereotactic radiotherapy for patients with uncontrolled acromegaly," Canadian Journal of Neurological Sciences, vol. 36, no. 4, pp. 468-474, 2009.

[59] S. Roug, A. K. Rasmussen, M. Juhler et al., "Fractionated stereotactic radiotherapy in patients with acromegaly: an interim single-centre audit," European Journal of Endocrinology, vol. 162, no. 4, pp. 685-694, 2010.

[60] K. Kajiwara, K. Saito, K. Yoshikawa et al., "Image-guided stereotactic radiosurgery with the CyberKnife for pituitary adenomas," Minimally Invasive Neurosurgery, vol. 48, no. 2, pp. 91-96, 2005.

[61] B. K. Roberts, D. L. Ouyang, S. P. Lad et al., "Efficacy and safety of CyberKnife radiosurgery for acromegaly," Pituitary, vol. 10, no. 1, pp. 19-25, 2007.

[62] M. Mitsumori, D. C. Shrieve, E. Alexander III, U. B. Kaiser, P. M. Black, and J. S. Loeffler, "Initial clinical results of linacbased stereotactic radiosurgery and stereotactic radiotherapy for pituitary adenomas," International Journal of Radiation Oncology Biology Physics, vol. 42, no. 3, pp. 573-580, 1998. 


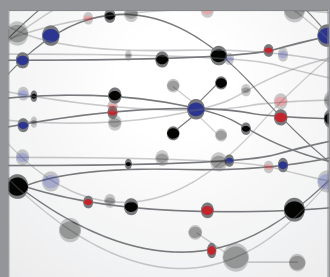

The Scientific World Journal
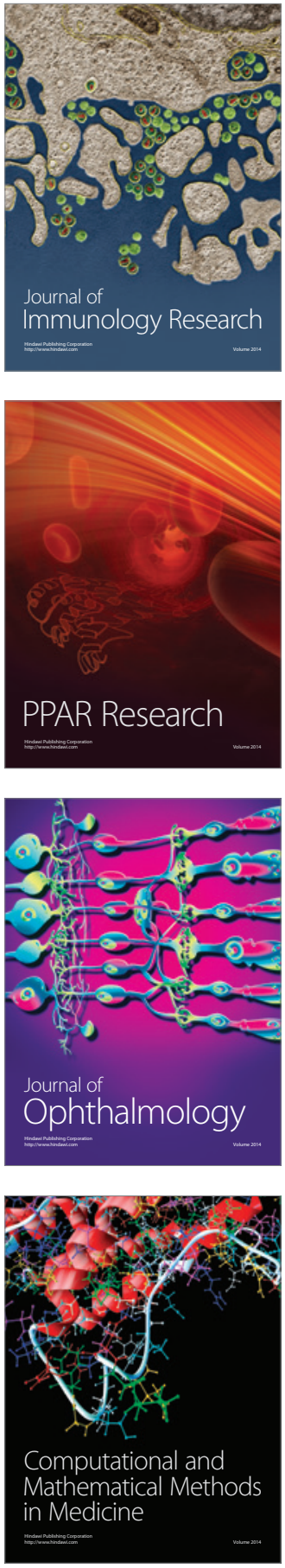

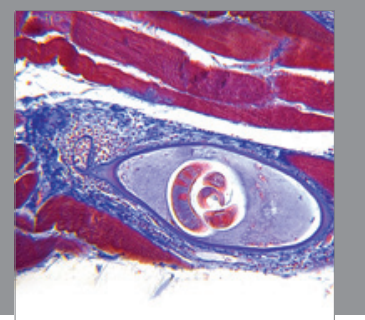

Gastroenterology

Research and Practice
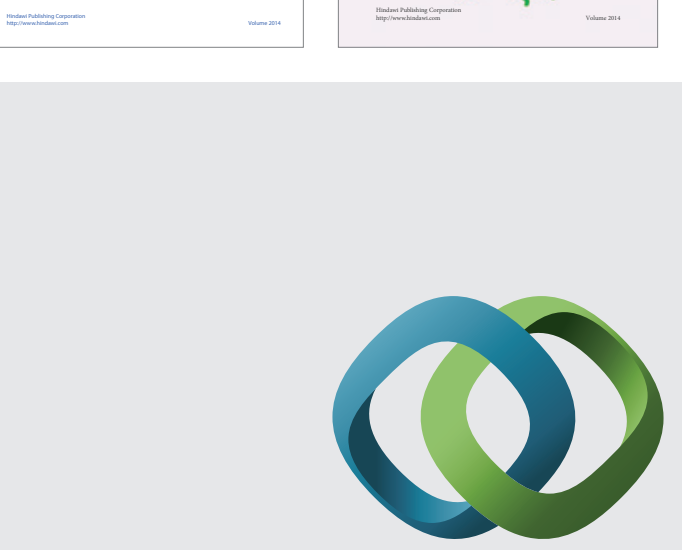

\section{Hindawi}

Submit your manuscripts at

http://www.hindawi.com
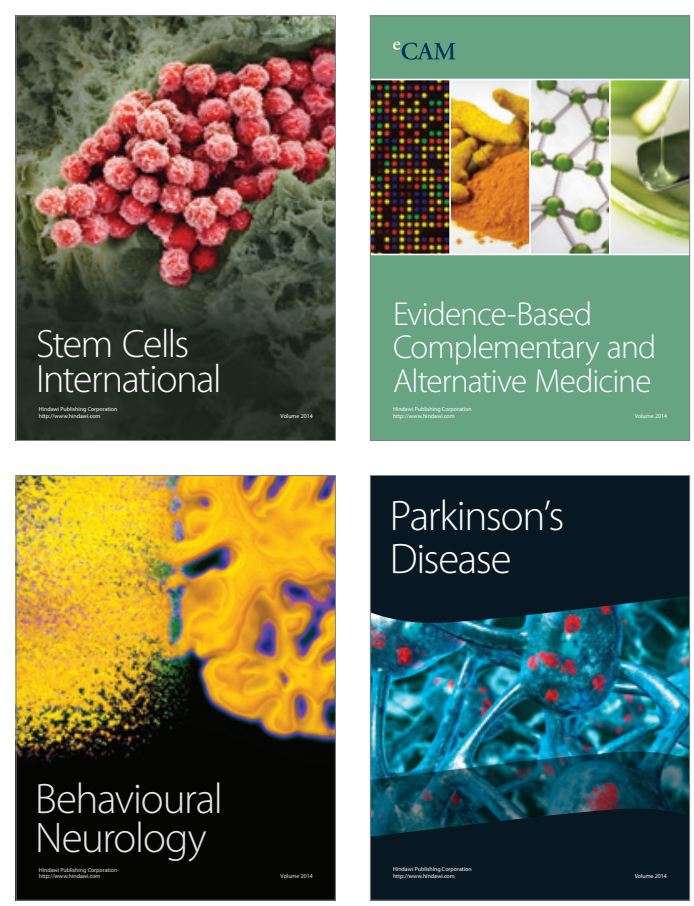

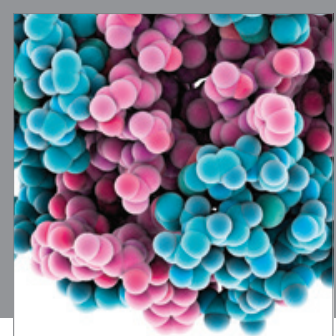

Journal of
Diabetes Research

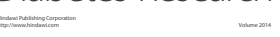

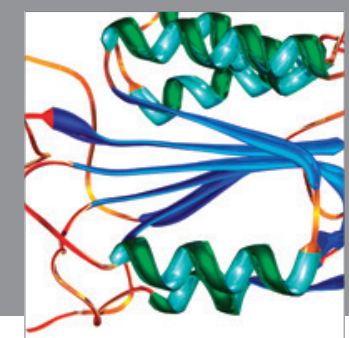

Disease Markers
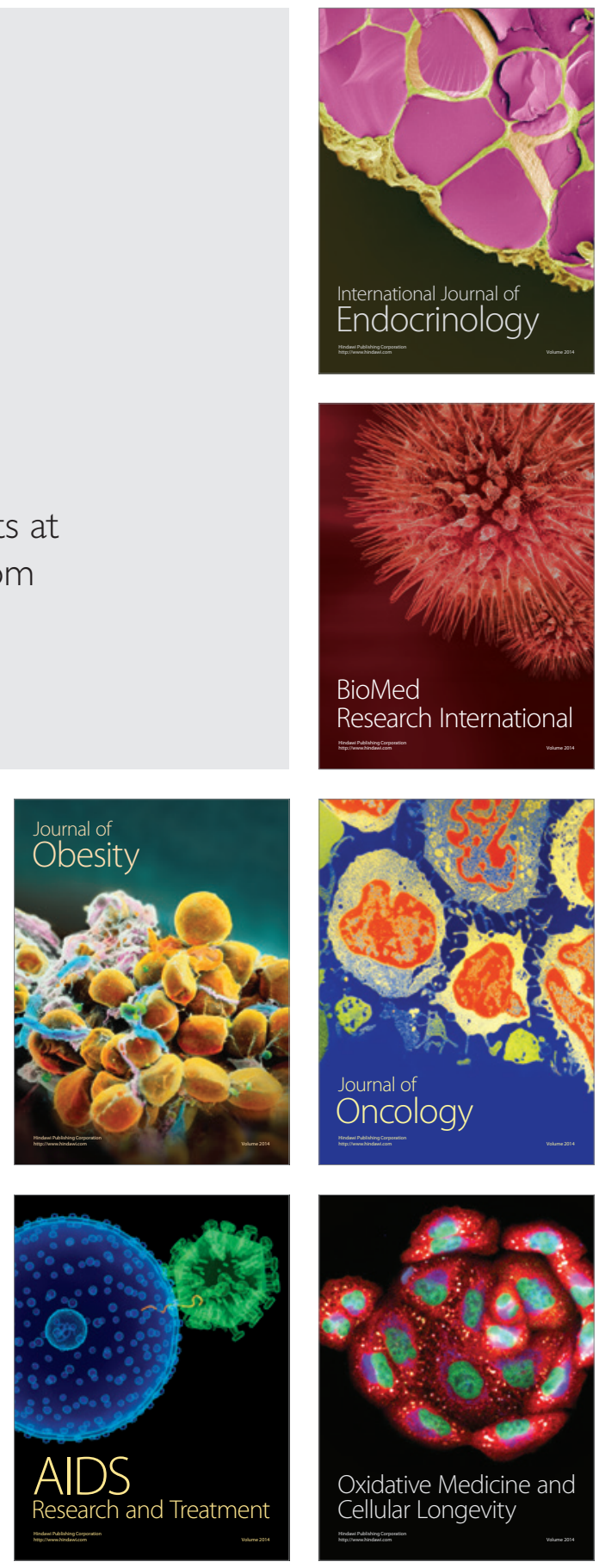